\title{
EFFECTS OF AGE, ETHNICITY AND HEALTH BEHAVIOURS ON THE PREVALENCE OF ADVERSE BIRTH OUTCOMES IN TAIWAN - ERRATUM
}

\author{
SHU-CHUAN WANG AND MUNG-CHIH LEE
}

doi:10.1017/S0021932012000260, Published by Cambridge University Press, 07 June 2012

In the published version of the article by Wang and Lee (2012), Meng-Chih Lee's name and affiliation are incorrect. The author line should read:

\section{SHU-CHUAN WANG* AND MENG-CHIH LEE $\uparrow$}

*Department of Medical Sociology and Social Work; Chung Shan Medical University, Taichung, Taiwan and $\dagger$ Department of Family Medicine, Taichung Hospital, National Department of Health, Institute of Medicine, Chung Shan Medical University, Taichung, Taiwan

\section{References}

Shu-Chuan Wang and Mung-Chih Lee (2012) Effects of age, ethnicity and health behaviours on the prevalence of adverse birth outcomes in Taiwan. Journal of Biosocial Science 44, 513-524. doi:10.1017/S0021932012000260. 